\section{Comparing Architects' Perceptions of the Usefulness of Digital Design Environments with their Aspirations for Sustainable Design in Australia}

\section{Rongrong $\mathrm{Yu}^{*}$}

School of Engineering and Built Environment, Griffith University, Gold Coast, Australia

\section{Michael J. Ostwald}

UNSW Built Environment, University of New South Wales, Sydney, Australia

${ }^{*}$ Corresponding author: rongrong.yu@uon.edu.au

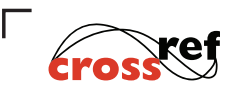
http://dx.doi.org/10.5755/j01.sace.29.2.28355
This paper uses a combined method - survey and semi-structured interviews - to evaluate the perceived effectiveness of digital design environments for supporting architects' sustainable design practices. In most contemporary firms, architects' sustainable design aspirations are reliant on the use digital design tools and associated computational platforms. Past research, however, suggests that a level of uncertainty exists about whether these tools and platforms are sufficient for this purpose. To investigate this issue in an Australian context, architects were invited to take part in an online survey to identify general trends and perceptions, leading to a series of semi-structured interviews, to analyse the issues in detail. The survey results $(n=70)$ suggest that despite considering sustainable design an important objective in their design practice, participants believe that digital design tools require further development and improvement. Detailed interviews $(n=15)$ then identified specific factors affecting the usefulness of digital design tools. These results enhance our understanding of Australian architects' experiences using digital design tools. It also contributes to improving the tools that support sustainable design practices throughout the architectural, engineering and construction industry.

Keywords: sustainable design practice, sustainable design digital tools, architectural design practice.

The United Nations' (2015) Sustainable Development Goals (SDGs) articulate the critical importance of sustainable design in the architectural, engineering and construction (AEC) industry. Buildings and construction generate $36 \%$ of global energy use and $39 \%$ of energy-related carbon dioxide (CO2) emissions (Abergel et al., 2017). These emissions have increased in recent years, reaching $10 \mathrm{GtCO} 2$ in 2019, the highest level on record (IEA, 2020). Sustainable design for the built environment seeks to reduce the ecological footprints of national and regional economies. In Australia, sustainable design principles are embedded in the graduate competencies and professional education of architects. They are also intrinsic to the Australian National Construction Code (NCC 2019) and to the State Environment Planning Policies (SEPPs) which govern building design. As such, like many other countries in the world, sustainable design practices are vitally important across Australia's AEC sector.
JSACE $2 / 29$

\section{Comparing}

Architects'

Perceptions of the Usefulness of Digital Design Environments with their Aspirations for Sustainable Design in Australia

Received 2021/01/22

Accepted after revision 2021/06/18

\section{Introduction}

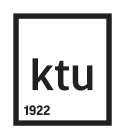

Journal of Sustainable Architecture and Civil Engineering Vol. 2 / No. 29 / 2021 pp. $5-20$

DOI 10.5755/j01.sace.29.2.28355 
Some of the most important mechanisms used to support AEC professionals to design in a sustainable way are software tools and platforms, which are collectively called "digital design environments" (DDEs). AEC professionals use DDEs to model environmental and socioeconomic issues when developing and constructing building designs (Akadiri et al., 2012). DDEs support architects and engineers to incorporate large volumes of contextual data - from energy, daylighting and hydraulics to planning codes, embodied energy and supply chain efficiency - into the performance analysis and optimization of design alternatives. Architects use DDEs to supplement their knowledge and experience with computational decision support systems that can provide real-time feedback during the optimisation and analysis processes (Coorey \& Jupp, 2014).

Past research examining DDEs and sustainable design has traditionally focused on technical capacity and accuracy (Peters, 2010). For example, research has identified DDE's low levels of user-friendliness and integration with CAD software (Weytjens \& Verbeeck, 2010), lack of capacity for life cycle assessment (Naboni, 2014), and problems associated with early design phases, excessive data-input, poor component libraries (Weytjens \& Verbeeck, 2010). Such ineffective aspects of DDEs in relation to sustainable design processes, may result in architects avoiding DDEs completely, or using them selectively and inexpertly during the design process, potentially leading to suboptimal performance of buildings. Such past research into DDEs has shaped their technical development, but technology adoption, acceptance and application decisions are as much a reflection of user experiences and organisational aspirations, as of actual DDE capacity to support sustainable design practice (Liu et al., 2018; Sepasgozar \& Davis, 2018). It is these last two factors - concerning designers' views about the effectiveness of DDEs and their aspirations for producing sustainable design - that are the catalysts for this paper. Furthermore, past research has shown that these perceptual and aspirational factors vary in different countries and in response to diverse industry contexts. Australian examples and research are well represented in technical research into DDEs, but there are fewer examples which consider perceptions and aspirations, and none which consider both. Thus, this paper addresses a research gap associated with the perceived effectiveness of digital design environments for supporting Australian architects' sustainable design goals.

To address this knowledge gap, this paper explores the overlap between two related research questions.

1. What are architects' attitudes to, and experiences of, using DDEs to design sustainable buildings?

2. How is sustainable design considered within architectural practice?

Rather than using these two questions to frame distinct and separate answers, this paper looks at the overlap between them, which provides an indication of where challenges and opportunities exist in architectural practice. For example, by combining answers to these questions it is possible to determine if architects' aspirations to produce sustainable buildings are supported by existing software tools. Conversely, the capacity of current tools may exceed organisational needs, providing scope for expansion of those needs for limited investment.

To answer these research questions, and examine what the implications of both are, this paper uses a combined method: survey and semi-structured interviews. The survey is of architects practicing in Australia $(n=70)$ and the interviews are of 15 experienced architects. The following sections provide an introduction to sustainable design practices, and a background on research into sustainable DDEs. Thereafter, the survey and interview methods are described, along with their application, results and interpretation. In the case of the survey, all results are reported, whereas only those interview results that support interpretation of the survey are included here. The paper concludes with a summary of results, their implications and methodological limitations. 


\section{DDEs and Sustainability}

One widely accepted definition of "sustainability" involves meeting "the needs of the present without compromising the ability of future generations to meet their own needs" (Report, 1987, p 41). Sustainability affects society, the environment and economy in different ways. The building industry is often identified as having the potential to substantially reduce energy requirements consumed in the construction process, used during a building life-cycle, and embodied in its demolition stage - through sustainable design (Akadiri et al., 2012; Biswas, 2014). The intention of sustainable design is to "eliminate negative environmental impact completely through skilful, sensitive design" (McLennan, 2004, p 5). In practice, to achieve this goal often requires architects to use DDEs to support the creation of efficient and responsive buildings, which meet environmental, social and economic demands. Typically, DDEs are used for modelling, analysis and optimisation of design options, in order to select the best solution from potential candidate solutions.

Sustainable design practitioners use multiple DDEs in their workplaces. Three interconnected and overlapping types of DDEs are a useful starting point for understanding them and the research undertaken in this field: (i) stand-alone sustainable design analysis and simulation tools, (ii) architectural design software that integrates building performance analysis or simulation, and (iii) parametric simulation tools. In the first category are analysis and simulation software for sustainable design which were, originally created as stand-alone tools. For example, EnergyPlus is opensource software, which has the advantage of flexibility. Sefaira is a component of the SketchUp platform, which has a broad user base and is relatively user-friendly and easy to learn. Ecotect was developed by Autodesk and in 2015 it was merged into Revit to support integration throughout the design process. Past research has used EnergyPlus for simulation of indoor climates (Buechler et al., 2017) and optimizing of cooling loads and daylighting levels in buildings (Samaan et al., 2018). From these examples it is also apparent that over time, the first category of DDEs is gradually merging into the second.

The second category of DDEs integrate sustainable design software into a larger platform. Examples of these DDEs include AutoCAD, SolidWorks and Microstation, all of which support fast numerical and geometric operations and include functions for modelling and simulating various aspects of sustainability. Building information modelling (BIM) platforms, like Autodesk Revit or ArchiCAD, also often feature integrated building performance analysis or simulation capacity, such as Green Building Studio. Xu et al. (2018) conducted a survey (20 responses) to examine the use of BIM in the AEC industry, particularly on the application of this software to sustainable design. Their results indicate that BIM software is predominately useful in the areas of analysis and visualization, but also supports orientation of projects and modelling of daylighting, ventilation and energy efficiency. Their research suggests that the most two common issues with these types of software are: designers' inadequate knowledge or practical experience using the software, and a lack of their clients' appreciation of the applications and benefits of the software.

The third category of DDEs for sustainability is parametric software. Yu et al. (2013) define parametric design as "a dynamic, rule-based process controlled by variations and constraints, in which multiple design solutions can be developed in parallel" ( $p$ 622). Two of the advantages of parametric design are that it can support decision optimisation and that some parametric tools can be customised to suit specific building performance requirements. Examples of parametric design tools are GenerativeComponents by Bentley and Digital Project by Gehry Technologies. Among the most commonly used parametric tools are Rhino, a stand-alone NURBS-based 3D modelling tool, and Grasshopper, a graphical algorithm editor which is integrated into Rhino as a plug-in. Some examples of Grasshopper plug-in tools used for energy simulation are Honeybee and Ladybug. Those tools assist designers to generate multiple compliant design solutions and then test building performance for each solution. However, evaluating and selecting design candidate solutions 
can be difficult and time-consuming (Wynn \& Clarkson, 2018). One of the advantages of parametric DDEs is that they can support serial and parallel optimization and analysis. In a parametric DDE, sets of input design variables are evolved automatically by an algorithm in order to achieve more compliant or optimal outputs. For example, contextual data such as sunlight direction can be input and analysed within a DDE. Sustainability performance analysis of this type is studied in various ways. For example, multi-parametric façade elements in a BIM model can be examined, so that designers can better consider energy performance while they are modelling geometries (Schlueter \& Thesseling, 2008). Bernal (2011) proposed a design model that combines parametric modelling technologies with a performance-based design paradigm. With similarities to Schlueter and Thesseling's (2008) model, Bernal provides real-time feedback on the building performance index. He et al. (2020) explored the use of a parametric design, simulation and analysis method (integrating computational fluid dynamics) to simulate wind environments for architectural design.

\section{Research into DDEs and Sustainability}

To a significant extent, the effectiveness of sustainable design practice is tied up in the capacity of DDEs to answer users' needs. The research cited in each of the three types of DDEs above tends to be technical in nature, considering solutions to improve building performance modelling (He et al., 2020; Schlueter \& Thesseling, 2008). In contrast, multiple studies have examined the reasons why DDEs have not been more widely adopted, and these point to problems of individual perception and to organisational factors (Sepasgozar and Davis 2018; Liu et al. 2018). Such human factors can differ between regions, highlighting the need for national or regional studies into both sustainable design practices and architects' perceptions of the usefulness of DDEs for supporting sustainable design.

For example, utilising focus group interviews (26 participants), Martek et al. (2019) investigated four organisational and contextual barriers to creating sustainable buildings in Australia: (i) problems of socio-spatial embedding, (ii) lack of end-user demand, (iii) limited user awareness and (iv) industry. Reflecting several of these problems, Whittem and Roetzel (2019) explored postoccupancy practices in Australia, through interviews with six practitioners, identifying three barriers: client's attitudes to sustainability, the impacts of "cost-engineering" on building performance, and procurement and contractual methods which discourage detailed modelling and post-completion assessment. These barriers, and availability of appropriate DDEs, are factors in Australia's capacity to conform to the UN's SDGs (Loh et al. (2020). Soebarto et al. (2015) conducted an online survey with participants in Australia, UK, India and USA, to explore architects' views on the difficulties of using building performance simulations (BPS). Results of their study suggest that most architects do not include BPS in their design process. Some of the reasons for this include the high cost of software, the cost of outsourcing BPS to external consultants, and architect's contractual fee structures. In an international study, Oliveira et al. (2017) used semi-structured interviews and focus groups (26 participants) to investigate architects' early-stage design decisions when using energy modelling tools in their design practice. Naboni (2014) interviewed sustainable design experts from ten leading architectural companies, showing that these architectural firms have design strategies and digital tools in place to facilitate their sustainable design, agendas. Weytjens and Verbeeck (2010) used interviews with nine architects and a survey to examine the use of energy evaluation tools in the architectural industry, finding that better tools and DDEs are needed.

The studies described in this section are just a few examples of the extensive body or technical research into DDEs for sustainable design that exist, as well as research into the barriers to DDE adoption for such purposes. In such research it is notable that in Australia, as in most of the international research, perceptual and organisational issues are typically not covered. A further observation is that only one of the studies cited in the previous section had more than 20 participants, which partially reflects the limited pool of expert respondents in most countries, 
including Australia. To respond to this situation, this paper is focused on the junction between architects' perceptions of, or aspirations for, sustainable design and their views about the capacity of DDEs to assist sustainable design. The combined method used in this paper balances the need for in-depth data gathering with a survey to attract a larger number of responses than are found in most previous studies.

This research employs a combined method - online survey and semi-structured interviews - to explore two research questions about (1) architects' experiences of, and attitudes to using DDEs to design sustainable buildings, and (2) the ways sustainable design is considered within architectural practice. The specific questions developed for both the survey and the interviews are synthesised from the literature reviewed. These questions combine general, demographic or fact-finding queries, with more nuanced and focused prompts.

\section{Survey}

Despite small response rates, research into DDEs in architecture often employs surveys to comment on broad trends in the field. For the present paper, an online survey containing 25 questions was sent to people employed in architectural practices in Australia. The survey notes and explanations made it clear that it was seeking people who (i) had used DDEs to support the production of sustainable designs and (ii) possessed professional qualifications in the architectural field. These factors limited the potential number of responses but also sought to find the most experienced participants who could provide the most valid and informed answers. The survey included multiple choice questions, Likert-scale questions and "open text" questions. Some of the questions were 'general' in nature, to construct a broader picture of the field, whereas others addressed specific issues aligned to the aims of this paper. There were four parts to the questionnaire.

1. Demographic questions (age, gender, location and specific design area).

2. Participants' views regarding the use of DDEs in their architectural design practices (including digital design tools applied in various design stages, the benefits of using digital design tools, etc). This section provides context for the next two, by asking broad questions about participant's experience using DDEs.

3. Architects' evaluation of sustainable design goals and applications within their practices (including whether or not their workplace has been actively pursuing sustainability objectives, and whether it forms an important part of their strategic plan). This section addresses research question 2.

4. Architects' experiences using DDEs to support sustainable design practices (including which particular sustainable DDEs they use, at what design stages they are used, which tool features are considered most important, and whether or not the current sustainable DDEs are considered helpful in achieving the architect's sustainable design goals). This section addresses research question 1.

\section{Semi-structured Interviews}

The interview has been the most common method used in past research to investigate Australian architects' attitudes to sustainability and technology. Interviews, which are ideal for collecting detailed responses to issues, can be semi-structured, lightly structured or in-depth (Mason, 1994). The semi-structured interview calls for the use of predesigned questions, which focus the participant's answers on the desired information, while also giving them some flexibility to explore issues. For the present research, the interview questions were designed to respond to gaps identified in the literature about the conjunction between sustainable design practice and aspirations (future-focused) and digital design tools for supporting sustainable practice (present-focused). The interview questions allow for open responses and to develop a conversational interchange,

\section{Research Method}


revealing deeper aspects of the issue being investigated. Some questions were also designed with follow-up prompts or clarifications. Importantly, by setting the scope at the start of the interview, the more open-ended questions retained a focus on the key research themes. Table 1 shows the predesigned prompts including three background questions and 10 focused on the main themes.

\begin{tabular}{|c|c|c|}
\hline & \multicolumn{2}{|r|}{ Background Questions: } \\
\hline \multirow{14}{*}{$\begin{array}{l}\text { Interview } \\
\text { questions }\end{array}$} & 1 & How many years of professional architectural working experience do you have? \\
\hline & 2 & What types of buildings are your main focus? \\
\hline & 3 & Where are you currently working, and where have you worked previously? \\
\hline & \multicolumn{2}{|r|}{ Main Themes: } \\
\hline & 1 & What are the main digital tools you are using in your practice? \\
\hline & 2 & $\begin{array}{l}\text { What do you think of current digital tools, in terms of their capacity to support or challenge design thinking } \\
\text { and creativity? }\end{array}$ \\
\hline & 3 & $\begin{array}{l}\text { What do you feel is the extent, of the application of sustainable design principles in current architectural } \\
\text { design practice? }\end{array}$ \\
\hline & 4 & $\begin{array}{l}\text { Is sustainable design currently considered at every scale in your practice, in the projects that your } \\
\text { workplace undertakes? If not, then what obstacles are currently preventing that? In your experience do } \\
\text { clients care about sustainability? }\end{array}$ \\
\hline & 5 & $\begin{array}{l}\text { What do you think of current digital tools, in terms of their ability to support sustainable design? } \\
\text { What do you think are the biggest challenges currently in this area? }\end{array}$ \\
\hline & 6 & What do you think about the possible future directions of architectural design for sustainability? \\
\hline & 7 & $\begin{array}{l}\text { Do you predict that computational design tools will play an increasingly large part in the future of } \\
\text { sustainable design? } \\
\text { Do you think that advanced artificial intelligence (Al) computing, may eventually change the role of architects? }\end{array}$ \\
\hline & 8 & What do you think may be the future direction for sustainable design? \\
\hline & 9 & How could sustainable design principles be more widely applied? \\
\hline & 10 & $\begin{array}{l}\text { Do you think that computational design tools will play a more or less important role in promoting } \\
\text { sustainable design? }\end{array}$ \\
\hline
\end{tabular}

\section{Table 2}

Codes for interview content

\begin{tabular}{l|l}
\hline \multicolumn{1}{c}{ Main themes } & \multicolumn{1}{c}{ Codes } \\
\multirow{2}{*}{$\begin{array}{l}\text { Sustainable } \\
\text { design practice }\end{array}$} & Designer's current practice \\
\cline { 2 - 2 } & Clients \\
\cline { 2 - 2 } & Aspect of sustainable design considered \\
\cline { 2 - 2 } & Evaluation of sustainable design practices \\
\cline { 2 - 2 } Future of & Regulation \\
\hline \multirow{2}{*}{$\begin{array}{l}\text { sustainable } \\
\text { design }\end{array}$} & Variation between practices \\
\hline Digital design & Puture trend \\
\hline tools & Digital thinking and computational design \\
\cline { 2 - 2 } & Digital design tools \\
\hline & Improvement of digital design tools \\
\hline
\end{tabular}

For the present paper, participants in the online survey were invited to take part in a detailed, follow-up interview. Thus, like the survey respondents, interview participants were working in Australian architectural practices, possessed professional qualifications in architecture and had at least five years' experience using DDEs. The interviews typically took 30 minutes to complete and the content was transcribed and coded using NVIVO. Three main themes and 11 codes were developed from the literature review, and cross-referenced with the survey results. As with the survey, one set of codes is about background conditions and the other two address the research questions (Table 2 ). 
70 participants took part in the survey, although some did not complete all questions. For some questions there were as few as 57 complete responses, whereas for others it was 70 . Because of this, the data is typically reported here as the percentage of the total number of responses to the question. Participants included architectural specialists in residential $(n=33)$, commercial $(n=18)$, health $(n=8)$, recreational and educational building design $(n=18)$. Some $(n=6)$ participants also identified expertise in urban design, landscape architecture and interior design (note that participants were able to identify multiple specialist areas). Participants were based in multiple cities throughout Australia, although the majority were from Brisbane, Sydney and Melbourne. 69.7\% of the participants identified as male and $30.3 \%$ as female. Participants were mostly in their $30 \mathrm{~s}$ $(31.82 \%), 40 \mathrm{~s}(27.27 \%)$ or $50 \mathrm{~s}(25.76 \%)$, with relatively few in their $20 \mathrm{~s}(15.15 \%)$.

\section{Digital Design Tools in Architectural Design Practice}

The second section of the survey focused on participants' perceptions about DDEs. Questions focused on the specific tools they were using, the design stages they applied them to, the features participants favoured and their experiences using these tools. Participants were allowed to select multiple answers for this question, since they may use multiple DDEs in their design practice. Fig. 1 shows the digital tools participants used in their practices. Revit and SketchUp are the most commonly used DDEs, accounting for $57.81 \%$ and $48.44 \%$ respectively. These are followed by ArchiCAD (37.50\%) and AutoCAD (35.94\%). Geometric modelling-focused tools such as Rhino (12.50\%), Grasshopper (14.60\%) and 3DMax (17.19\%) were the lowest percentage. Other tools that designers used included the Adobe suite (Photoshop, Illustrator, InDesign), Lumion, Vectorworks, Navisworks, Dynamo, BIM 360, MicroStation, Vary and Enscape.

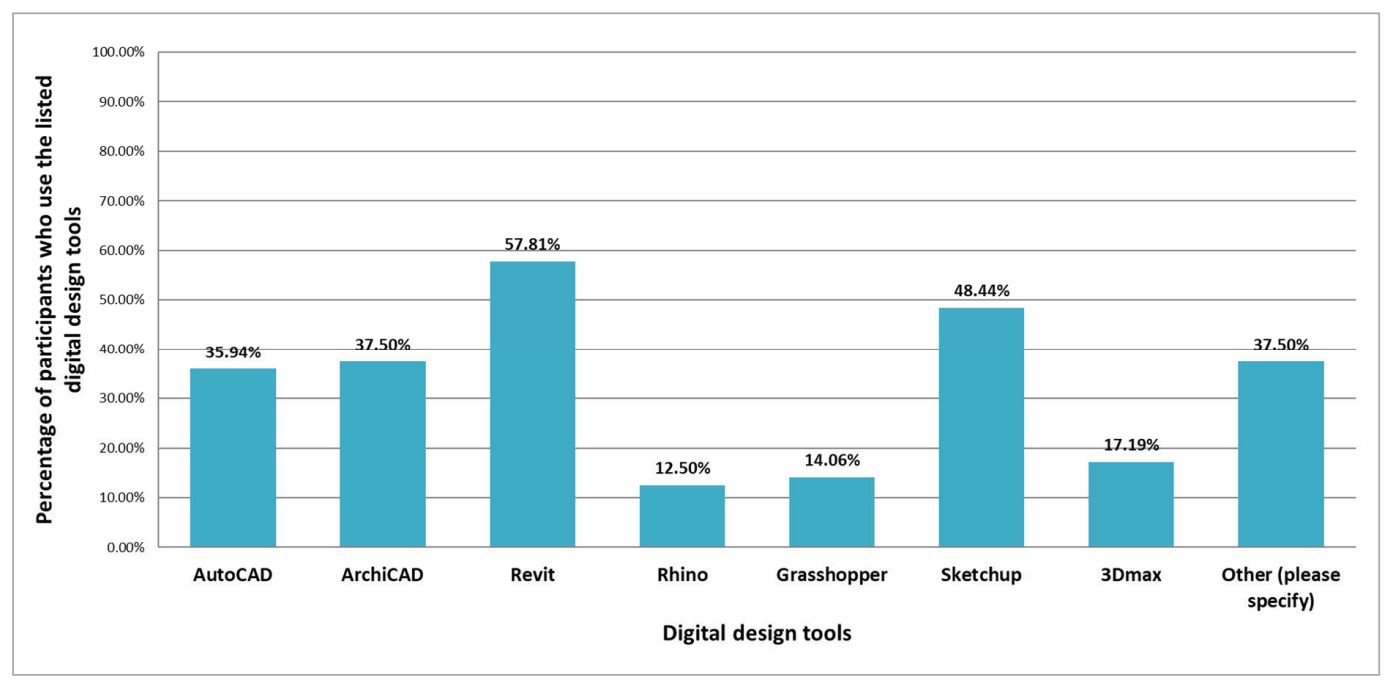

The digital tools participants commonly use across design stages (pre-design, concept design, schematic design, detail design and developed design) are identified in Fig. 2. Across these stages, participants mostly used Revit and ArchiCAD, except for pre-design and concept design stages, where SketchUp dominated. Revit is used more towards the later design stages (typically developed design). Additionally, in the open text responses participants mentioned that "it is not easy to use the available digital tools for the concept design stage".

In Fig. 3, participant's opinions about the benefits of using DDEs and the design processes that DDEs assist are identified. In this data, $63.33 \%$ of participants considered visual representation the most important benefit of using digital design tools. This is followed by multidisciplinary collaboration (11.67\%), intradisciplinary collaboration (10.00\%), flexible and friendly user interface (8.33\%)

\section{Results}

\section{Fig. 1}

Digital design tools used by participants (note that participants could select multiple tools) 
Fig. 2

Digital tools participants use in different design stages

Fig. 3

Uses of digital design tools (left). Design process which digital design tools assist (right)
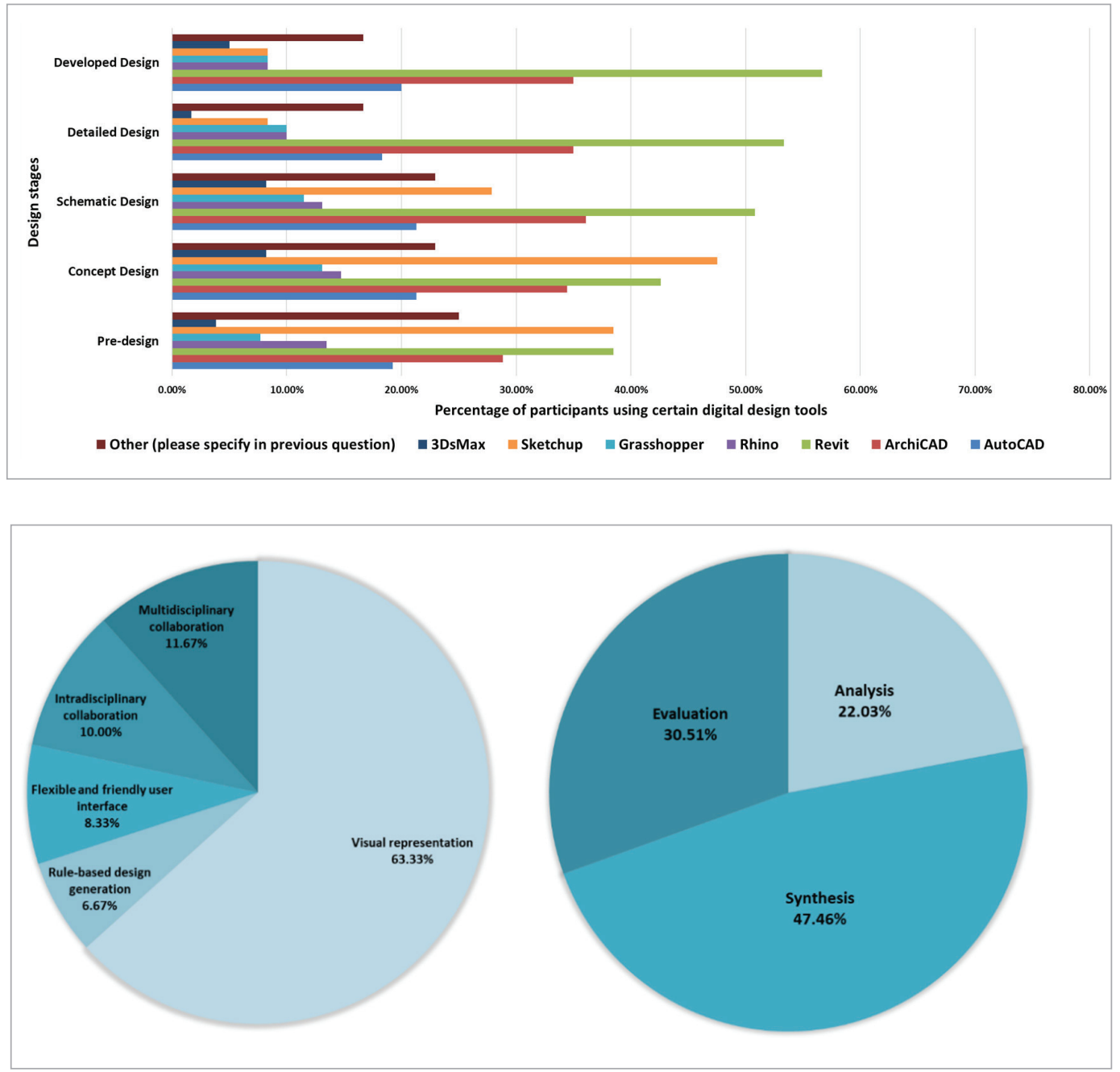

and rule-based design generation (6.67\%). In terms of the design process, synthesis is considered the most important process that these tools assist (47.46\%), followed by analysis (22.03\%) and evaluation (30.51\%). Synthesis in architecture refers to the merging of information that is relevant to the design project, to create appropriate architectural responses to the specified context. The cognitive importance of visual representation (63.33\%) is that in the early design stages it supports concept development by “off-loading cognition" (Schön \& Wiggins, 1992; Schön, 1992).

Table 3 reports the Likert scale results for participants' evaluation of current DDEs. Most participants agree that such tools, systems and platforms assist them to formulate sustainable design solutions. In answering the question about their proficiency in using these tools, and the impact of this, responses tended to be neutral and with less agreement. This result may also reflect some ambivalence about DDEs, as one participant commented: "overreliance on digital design can have a negative influence on the free-flowing nature of design. Software cannot replace good basic designs."

\begin{tabular}{c|l|c|c}
\hline & \multicolumn{1}{|c|}{ Question } & Mean & SD \\
\hline 1 & Digital design tools assist me in formulating my design solution. & 4.12 & 0.80 \\
\hline 2 & My proficiency level in the use of digital design tools has a big impact on my design. & 3.34 & 1.24 \\
\hline
\end{tabular}

$($ Strongly Agree $=5$, Agree $=4$, Neutral $=3$, Disagree $=2$, Strongly Disagree $=1)$ 
The open questions were included to explore participants' experiences using DDEs and not all participants chose to answer these. Two participants who did, stated that utilisation of these tools allowed them to integrate and optimise designs for better outcomes. Conversely, four participants expressed the view that modern technological tools were akin to a drawing board that can be used to produce design documents but should only support the design process not replace it. Two participants believed that digital design tools should support and facilitate transmission of ideas about site-specific and well-considered design outcomes, but rarely results in such approaches.

\section{Sustainable Design Goals in Architectural Practice}

The third section of the survey gathered participants' opinions regarding the application of sustainable design in their design practice (Table 4). From this data we can see that most participants agree that their workplace actively pursues sustainable objectives and that sustainability is important in their practice.

\begin{tabular}{l|l|c|c}
\hline \multicolumn{1}{|c|}{ Question } & Mean & SD \\
\hline 1 & $\begin{array}{l}\text { My workplace actively pursues sustainability objectives in relation to preliminary client } \\
\text { design work. }\end{array}$ & 3.95 & 0.89 \\
\hline 2 & Setting up sustainability objectives is an important part of my design practice. & 4.09 & 0.82 \\
\hline
\end{tabular}

$($ Strongly Agree $=5$, Agree $=4$, Neutral $=3$, Disagree $=2$, Strongly Disagree $=1)$

Fig. 4 identifies the applications or areas of sustainable design that participants considered most important. Participants were allowed to select multiple answers for this question. The results show that energy (38.60\%) and heating/cooling (26.32\%) are weighted more highly than other applications. Participants also stated in the open-text responses, that all aspects of sustainable design were important to them, including passive sun control, waste, ventilation and global footprint.

The open questions also asked participants' opinions about sustainable design in their practice. Four responded that they always try to incorporate passive solar design strategies and cross ventilation for heating and cooling, and consider this essential to a good design outcome. Two participants emphasised that a focus on local sustainable and healthy production and sourcing of materials and systems is crucial. There were also participants who noted that sustainable design is "not used heavily in practice".

\section{Evaluating DDEs in Sustainable Design Practice}

The final section of the survey examines the effectiveness of DDEs in sustainable design practice (Table 5). The data shows that participants generally had a positive attitude towards current DDEs, and tended to agree that they are helpful, especially for the design analysis and optimization processes to support sustainability. However, the mean score was only moderately positive (3.593.91), which suggests there is room for improvement and that DDEs could be even more effective for enabling sustainable design practices.
Table 4

Participant's evaluation of how sustainable design is applied in their practice

Fig. 4

Aspects of sustainable design considered to be most important 


\begin{tabular}{|c|c|c|c|c|}
\hline Tabl & & Question & Mean & SD \\
\hline \multirow{4}{*}{$\begin{array}{r}\text { Participants' } \\
\text { evaluation of DDEs for } \\
\text { sustainability in their } \\
\text { practice }\end{array}$} & 1 & Sustainable design digital tools are helpful with sustainable goal setting. & 3.69 & 0.84 \\
\hline & 2 & Sustainable design digital tools are helpful during design analysis. & 3.87 & 0.73 \\
\hline & 3 & Sustainable design digital tools are helpful during design optimisation. & 3.91 & 0.78 \\
\hline & 4 & $\begin{array}{l}\text { The sustainable design digital tools being used are effective in achieving sustainable } \\
\text { design goals. }\end{array}$ & 3.59 & 0.85 \\
\hline
\end{tabular}

$($ Strongly Agree $=5$, Agree $=4$, Neutral $=3$, Disagree $=2$, Strongly Disagree $=1)$

Fig. 5 shows the DDEs that participants use for sustainable design, and surprisingly it records that $65.52 \%$ do not personally use DDEs for sustainability modelling and support. This finding is in stark contrast to the aspirations and claims recorded previously in the survey, and it highlights either the lack of appropriate sustainable design tools or other barriers to adoption of DDEs for sustainable design. 10.34\% of the participants were using Rhino/Grasshopper, followed by Safaira (8.62\%) and Ecotect (8.62\%). Use of Vasary and Green Building Studio are each 5.17\% and Energyplus is $3.45 \%$. Participants also listed other tools they use including ArchiCAD for sun studies, Empirical Design Principle, Climate Consultant, Vasari, Dynamo and Refinery. Several participants noted that specialist external energy consultants are involved in their design projects, suggesting that sustainability modelling and analysis largely occur outside the design practices. Rhino and Grasshopper were used more frequently than traditional energy simulation tools in DDEs. This may be due to the flexible features of the parametric tools which allow for customisation for specific design project needs.

Fig. 5

Participant use of sustainable design digital tools

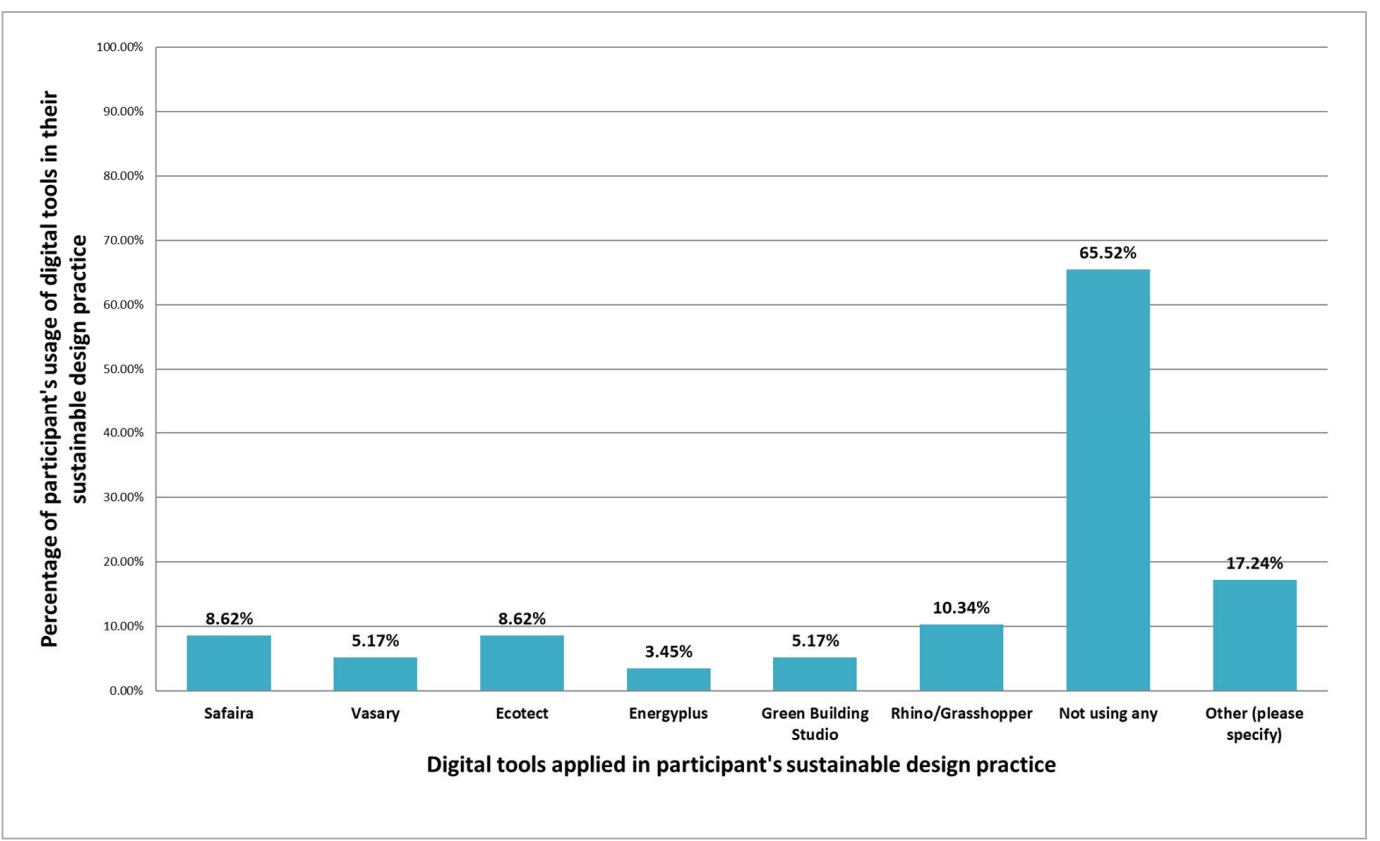

Fig. 6 shows the design stages in which participants typically use DDEs to support sustainability and their primary features that participants use. From these results we can see that DDEs are more likely to be applied in the concept design stage (29.82\%) when designers are developing their initial ideas. Schematic design (24.56\%) is the next more common, followed by developed design (17.54\%), pre-design (15.79\%) and detail design (12.28\%). The primary features of DDEs that 


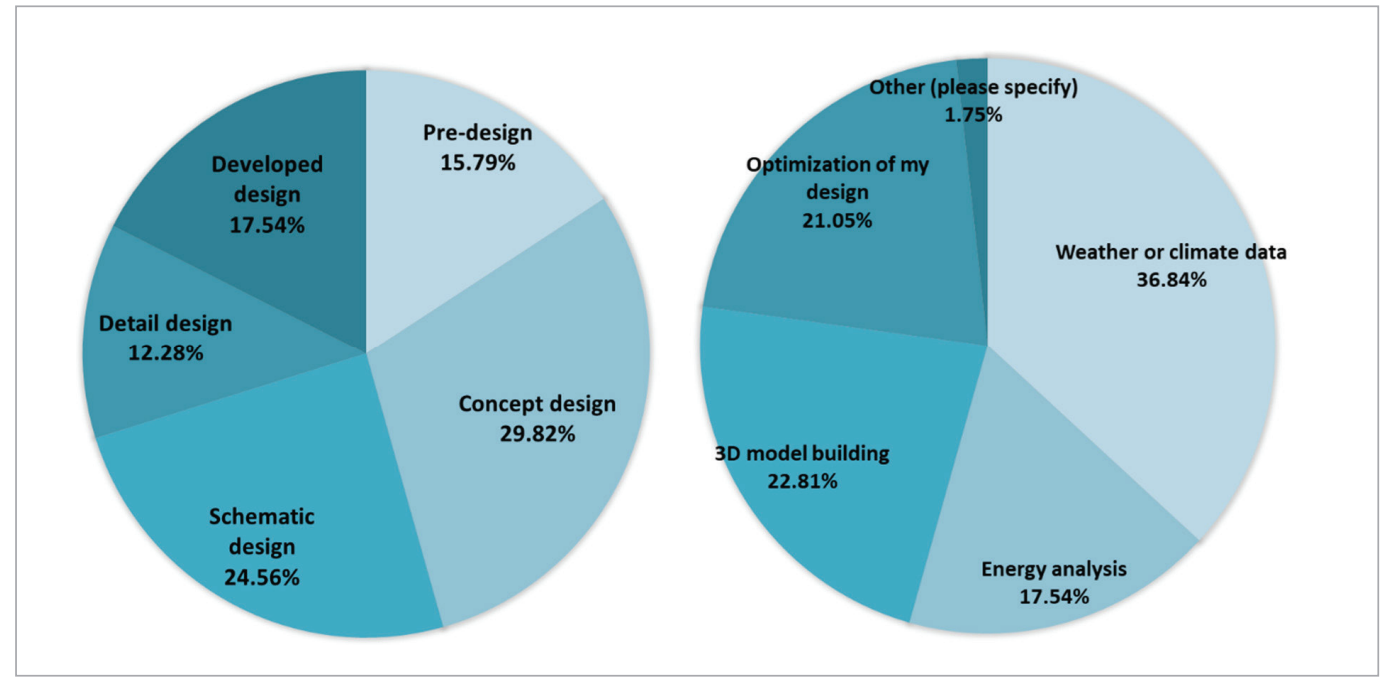

participants use most often are weather or climate data (36.84\%) and 3D model building (22.81\%), followed by optimization of design (21.05\%) and energy analysis (17.54\%).

Focusing on sustainable design, Fig. 7 shows the features of DDEs that participants most favour. $31.58 \%$ consider the most important feature of DDEs is their integration of a best practice design knowledge base, to assist designers in intelligent decision making. That feature is followed by support for high-quality 3D modelling of proposals (15.79\%). Only $12.28 \%$ of participants identify energy analysis results and friendly user interfaces. Based on these results, a capacity for transferable export/import from other design software was considered the least critical (3.51\%).

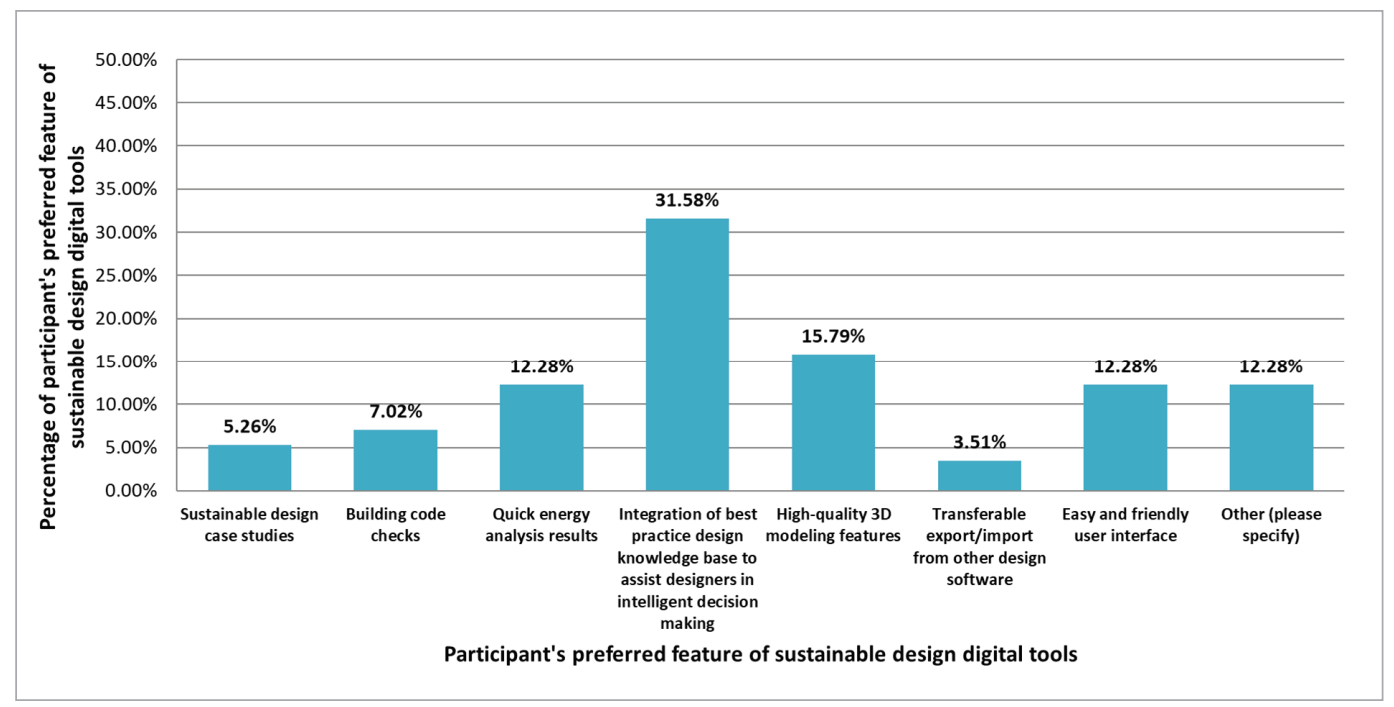

The open questions in the survey were used to explore participants' views about current DDEs. Some participants viewed Autodesk's move to a subscription licensing model as undermining their sustainable design goals, while Grasshopper's open-source approach was more supported. Participants also argued that it was important that tools possess a capacity to present information to clients, in such a way as to explain sustainable principles and easily modify designs based on those principles. This was also considered necessary for balancing costs and time investment in such a way that clients can appreciate and embrace sustainability. Some participants noted

\section{Fig. 6}

The design stage in which the participants most typically apply DDEs for sustainability (Left). The primary feature of DDEs that participants apply within their sustainable design practice (Right)

Fig. 7

Primary DDE features that participants favour 
that a seamless data exchange between software systems would be beneficial. Other comments touched upon specific building codes (NCC and Australian standards) discussing embodied energy in design and construction options for single residences, and a shift in the goals of state-wide certification systems (BASIX), including targets for construction waste. Participants expressed the view that there was a need to reward higher sustainability "ratings" or "scores" with incentives, rather than focusing on minimum standards. Participants also voiced the opinion that DDEs shouldn't be a replacement for design professionals having fundamental knowledge of sustainable design practices from the outset.

\section{Selected Interview Results}

Two sets of interview coding results are reported in this section to support interpretation of the survey results. Fig. 8 shows the coding percentage of the 15 interviewees' answers. This data indicates that the most discussed theme was the use of digital design tools in architects' current practice. This is followed by: evaluation of sustainable design practice, aspects of sustainable design considered and promoting sustainable design. This confirms that digital design tools play an important role in architects' design practice and that architects do consider sustainable design issues during the design process. Furthermore, while both "designers' current practice" and "digital design tools" were, for obvious reasons, central issues explored in the interviews, several others issues were also common. For example, the capacity of DDEs to support "evaluation of design options", their capacity to "promote sustainable design", and the ways they support "design thinking" were all common, and arguably closely related, themes. Conversely, "budget", "clients briefs" and "regulations" - all prominent factors identified in technology adoption models - were rarely mentioned. Variation between practice were mentioned by some participants since for sustainable design practice different practices adopted different approaches (some were due to the scope of service they provide).

Fig. 8

Coding of interview content

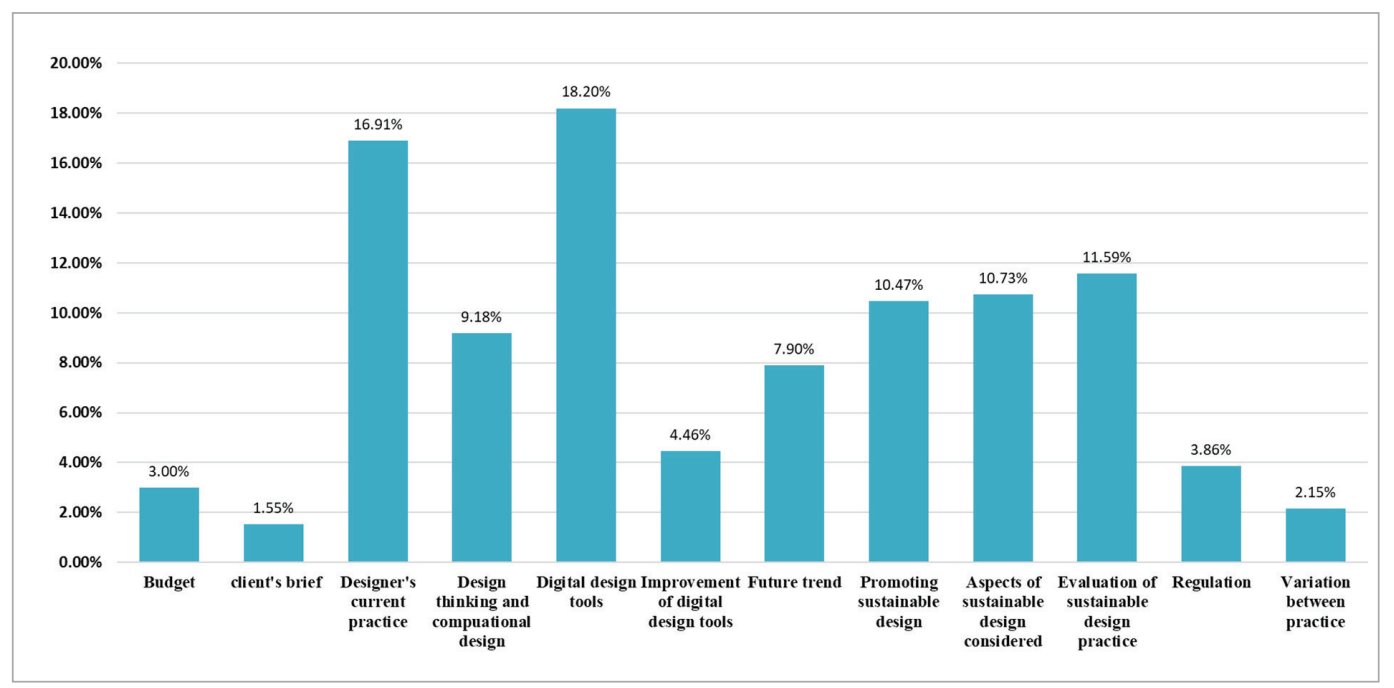

Fig. 9 shows the negative or positive experience in each of the codes. These results indicate that on average, architects had more negative than positive experiences when considering sustainable design practice, digital design tools, their current practice and available budgets. Indeed, only DDE's capacity to "promote sustainable design", support "future trends" and improve "client briefs" achieved more positive than negative mentions. As an example of why these results are useful, budgets were only rarely mentioned in the interviews (Fig. 8), but of these, 11 out of 13 identified financial impediments to sustainable design and the use of DDE. Similarly, regulation, which was also only rarely mentioned, was overwhelmingly viewed as a negative influence on sustainable 
design and use of DDEs. The capacity of digital design tools to support sustainable design received the highest positive and negative results, although organisational incapacity to use DDEs or achieve sustainable goals was the second greatest negative. For the category "variation between practice", responses were mostly neutral although some referred to negative experiences. This is because some participants noted that sustainable design was not considered important by some design practices. One participant commented: "Australia's been very slow in adopting minimum performance standards for buildings, ... New Zealand was doing it for houses 15 years before we were". These last two sets of results provide additional nuance when reviewing the survey results, because both were regarded as important factors in the survey. But in the interviews, the capacity to use DDEs to achieve sustainable outcomes, and to meet practice objectives, prompted more pessimistic than optimistic answers.

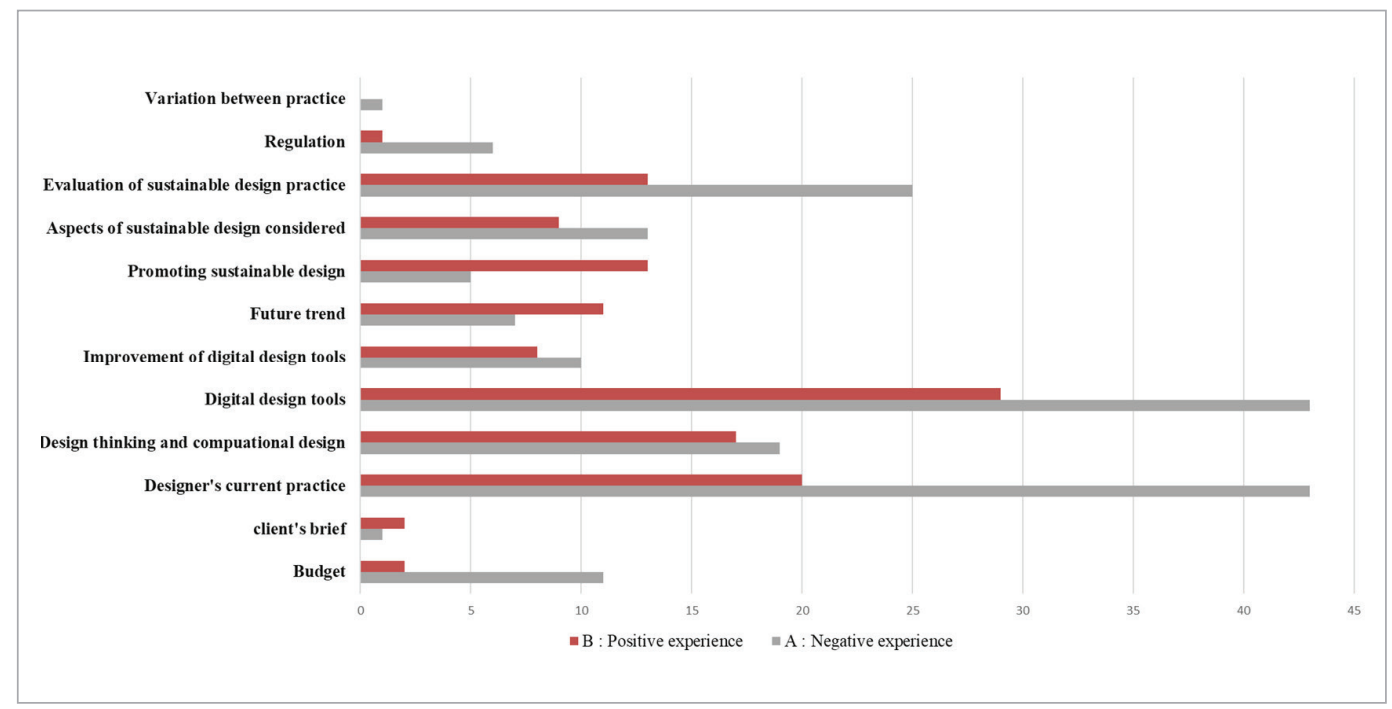

This paper set out to investigate the two research questions and the relationship between them. First, what are architects' attitudes to, and experiences of, using DDEs to design sustainable buildings? Second, how is sustainable design considered within architectural practice? These two questions have both been separately considered in the past, and in other countries, but not recently and not in an Australian context. Furthermore, the combination of questions supports an investigation of correlation or symmetry in relation between perceptions of DDE capacity and aspirations for sustainable design.

Starting with the first question, the main digital design tools used were Revit and SketchUp; the former of which was used across all design stages, while the latter was mainly used at the concept design stage. Integrated sustainable design tools - Ecotect, Green Building Studio and Sefaira - exist for both Revit and SketchUp, however most architects (65.52\%) admitted to not using these for complex environmental modelling, but rather outsourcing them. Among DDEs, the embedded sustainability tools in Rhino and Grasshopper were applied more often than traditional, stand-alone energy simulation tools, which suggests a need for flexible customised parametric design tools in facilitating sustainable design. Stronger integration of sustainable tools in DDEs was also identified as the main way of facilitating architects' decision-making for design, a finding which reflects that of past research (Jansen and Bosch (2005). Architects generally do not have the time nor inclination to learn new specialised software systems. For existing DDE, the data identifies interoperability as a weakness, and that visual representation and collaboration in sustainable design were the most needed features of DDEs for architects.

\section{Fig. 9}

The negative or positive experience in each of the coding 
For the second question, and not surprisingly, most architects argued that their workplaces actively pursued sustainable objectives. Furthermore, in relation to specific aspects of sustainable design goals, most participants confirmed that all aspects of sustainable design were important, including heating/cooling, passive sun control, waste/ventilation/energy and global footprint. When considering these factors in parallel with the first research question, several areas of asymmetry or misalignment are evident. For example, while participants strongly affirmed their aspirations for designing sustainable buildings, they identified significant barriers, most of which were technical (e.g. about DDE capacity) rather than about cost, time, or legislation. Because the context for both the surveys and interviews was DDEs and sustainability, such an emphasis may be explained as a form of confirmation bias, but the 'positive/negative' codings suggest that it may be more than this. Possibly more than budget, legislation or organisational factors - the lack of integrated, easy to use tools for modelling sustainability in DDEs may be a major factor. For example, participants expressed relatively positive attitudes towards current DDE tools for sustainability and generally agreed that current tools are helpful, but also admitted to now using advanced tools for design analysis and optimization processes. The results also indicate that there is significant room for improvement in current DDEs' capacity to assist architects' sustainable design practices.

Additionally, most architects stated that both regulations and their client's requirements are vitally important in driving their sustainable design goals. Although outsourcing of building performance analysis is financially beneficial, the extra communication required with external consultants sometimes delays the design process and can make their processes more complicated. Outsourcing of building performance analysis tasks can also lead to missed opportunities for conducting such analysis tasks during the early stages of the design process, which could benefit the design as a holistic entity, rather than serving to simply obtain a certificate from a consultant to meet the regulatory requirement. Therefore, to a certain extent, architects themselves need to be able to conduct building performance analysis and optimisation. Another issue to be mindful of is the practical operability of current DDEs for sustainable design, as one architect stated he hoped for the existence of "a tool that could come into my skillset that I could use... [and for which] I didn't need to do huge amounts of training".

There are several practical limitations to this research. Firstly, 70 survey responses and 15 interviews is not a particularly large sample (although it is still larger than all but one of the previous studies undertaken into this particular issue and context). The response rate was partially a result of the limited pool of architects currently working within Australia and who are experienced in both sustainable design and associated software tools and platforms. The low numbers of participants also preclude more detailed statistical analyses or considerations of issues on demographic grounds (by gender, age or location). An expansion of this study could include larger samples from other international regions, to provide more statistically significant results.

The results of this paper seek to enhance our understanding of architects' experiences in relation to achieving sustainable design goals using DDEs. It provides insights and new knowledge about the processes that support sustainable design solutions and architects' aspirations to achieve them. These findings can potentially identify new strategies for increasing the application and adoption of sustainable design principles, and facilitate enhancements to sustainable design practices.

\section{References}

Abergel, T., Dean, B., \& Dulac, J. (2017). UN Environment and International Energy Agency (2017): Towards a zero-emission, efficient, and resilient buildings and construction sector. Global Status Report 2017.

Akadiri, P. O., Chinyio, E. A., \& Olomolaiye, P. 0. (2012). Design of A Sustainable Building: A Con- ceptual Framework for Implementing Sustainability in the Building Sector. Buildings, 2(2), 126-152. https://doi.org/10.3390/buildings2020126

Bernal, M. (2011). Analysis model for incremental precision along design stages Proceedings of the 16th International Conference on Computer Aided 
Architectural Design Research in Asia(CAADRIA), Newcastle, Australia.

Biswas, W. K. (2014). Carbon footprint and embodied energy consumption assessment of building construction works in Western Australia. International Journal of Sustainable Built Environment, 3(2), 179186. https://doi.org/10.1016/j.ijsbe.2014.11.004

Buechler, E., Pallin, S., Boudreaux, P., \& Stockdale, M. (2017). Probabilistic modeling of the indoor climates of residential buildings using EnergyPlus. Journal of Building Physics, 41(3), 225-246. https:// doi.org/10.1177/1744259117701893

Coorey, B. P., \& Jupp, J. R. (2014). Generative spatial performance design system. Al EDAM, 28(Special Issue 03), 277-283. https://doi.org/10.1017/ S0890060414000225

He, Y., Schnabel, M. A., \& Mei, Y. (2020). A novel methodology for architectural wind environment study by integrating CFD simulation, multiple parametric tools and evaluation criteria. Building Simulation, 13(3), 609-625. https://doi.org/10.1007/s12273-019-0591-8 IEA. (2020). Tracking Buildings 2020.

Jansen, A., \& Bosch, J. (2005, 6-10 Nov. 2005). Software Architecture as a Set of Architectural Design Decisions. 5th Working IEEE/IFIP Conference on Software Architecture (WICSA'05),

Liu, D., Lu, W., \& Niu, Y. (2018). Extended Technology-Acceptance Model To Make Software Construction Systems Successful. Journal Of Construction Engineering And Management, 144(6), 1-10. https:// doi.org/10.1061/(ASCE)C0.1943-7862.0001487

Loh, S., Foth, M., Caldwell, G. A., Garcia-Hansen, V., \& Thomson, M. (2020). A more-than-human perspective on understanding the performance of the built environment. Architectural Science Review, 1-12. https://doi.org/10.1080/00038628.2019.1708258

Martek, I., Hosseini, M. R., Shrestha, A., Edwards, D. J., \& Durdyev, S. (2019). Barriers inhibiting the transition to sustainability within the Australian construction industry: An investigation of technical and social interactions. Journal of Cleaner Production, 211, 281292. https://doi.org/10.1016/j.jclepro.2018.11.166

Mason, J. (1994). Linking qualitative and quantitative data analysis. In Analysing qualitative data; pp. (pp. 89-110). London, Routledge. https://doi. org/10.4324/9780203413081_chapter_5

McLennan, J. F. (2004). The Philosophy of Sustainable Design: The Future of Architecture. Ecotone. https:// books.google.com.au/books?id=-Qjadh_OleMC

Naboni, E. (2014). Sustainable Design Teams, Methods and Tools in International Practice. DETAIL Green, 14, 68-73.
Oliveira, S., Marco, E., Gething, B., \& Robertson, C. (2017). Exploring Energy Modelling in Architecture Logics of Investment and Risk. Energy Procedia, 111, 61-70. https://doi.org/10.1016/j.egypro.2017.03.008

Peters, B. (2010). The new Elephant House. In R. Woodbury (Ed.), Elements of Parametric Design. London: Routledge.

Report, B. (1987). World Commission on Environment and Development (WCED): Our common future.

Samaan, M. M., Farag, O., \& Khalil, M. (2018). Using simulation tools for optimizing cooling loads and daylighting levels in Egyptian campus buildings. HBRC Journal, 14(1), 79-92. https://doi. org/10.1016/j.hbrcj.2016.01.001

Schlueter, A., \& Thesseling, F. (2008). Balancing Design and Performance in Building Retrofitting: A Case Study Based on Parametric Modeling. Proceedings of the 28th Annual Conference of the Association for Computer Aided Design in Architecture (ACADIA)

Schön, D., \& Wiggins, G. (1992). Kinds of seeing and their functions in designing. Design Studies, 13(2), 135-156. https://doi.org/10.1016/0142694X(92)90268-F

Schön, D. A. (1992). Designing as reflective conversation with the materials of a design situation. Knowledge-Based Systems, 5(1), 3-14. https://doi. org/10.1016/0950-7051(92)90020-G

Sepasgozar, S. M. E., \& Davis, S. (2018). Construction Technology Adoption Cube: An Investigation on Process, Factors, Barriers, Drivers and Decision Makers Using NVivo and AHP Analysis. Buildings, 8(74), 1-31. https://doi.org/10.3390/buildings8060074

Soebarto, V., Hopfe, C. J., Crawley, D., \& Rawal, R. (2015). Capturing the views of architects about building performance simulation to be used during design processes 14th International Conference of the International Building Performance Simulation Association, , Hyderabad, India.

Weytjens, L., \& Verbeeck, G. (2010). Towards "architect-friendly" energy evaluation tools Proceedings of the 2010 Spring Simulation Multiconference, Orlando, Florida. https://doi. org/10.1145/1878537.1878724

Whittem, V., \& Roetzel, A. (2019). Learning from built projects - sources of post occupancy feedback used by architects in Victoria, Australia. Intelligent Buildings International, 1-16. https://doi.org/10.10 80/17508975.2019.1695192

Wynn, D. C., \& Clarkson, P. J. (2018). Process models in design and development. Research in Engineer- 
ing Design, 29(2), 161-202. https://doi.org/10.1007/ s00163-017-0262-7

Xu, C., Hu, X., Tivendale, L., Liu, C., \& Hosseini, M. R. (2018). Building information modelling in sustainable design and construction. International Journal of Sustainable Real Estate and Construction
Economics, 1, 164. https://doi.org/10.1504/IJSRECE.2018.10013438

Yu, R., Gu, N., \& Ostwald, M. (2013). Comparing designers' problem-solving behavior in a parametric design environment and a geometric modeling environment [Article]. Buildings, 3(3), 621-638. https://doi.org/10.3390/buildings3030621

\section{About the} Authors

\section{RONGRONG YU}

\section{Lecturer}

Architecture \& Design, School of Engineering and Built Environment, Griffith University, Gold Coast, Australia

\section{Main research area}

Computational design, design cognition

\section{Address}

Griffith University, G39 Room 3.30, Gold Coast

Campus, Southport, QLD, 4222, Australia

E-mail: rongrong.yu@uon.edu.au

Phone: +61 755527618

Orcid ID: 0000-0001-6948-9543

\section{MICHAEL J. OSTWALD}

Professor, Associate Dean of Research

\section{Main research area}

Architectural computing and visualisation methods, Data visualisation and computational design

\section{Address}

UNSW Built Environment, Faculty of Arts, Design \& Architecture, Room 4026, Level 4, Red Centre West Wing, UNSW SYDNEY 2052

E-mail: m.ostwald@unsw.edu.au

Phone: 0290659708

Orcid ID: 0000-0001-6210-6984 